\title{
SANTO TORIBIO DE MOGROVEJO (1538-1606) EN QUIVES ${ }^{1}$
}

José Antonio Benito

Los Santos son los verdaderos portadores de luz en la bistoria, porque son bombres $y$ mujercs de fe, esperanza y amor.

La vida de los Santos no comprende solo su biografia terrena, sino tambièn sib vida y actuación en Dios después de la muerte. En los Santos es evidente que, quien va hacia Dios, no se aleja de los hombres, sino que se hace realmente cercano a ellos.

Benedicto XVI, Deus caritas est

1 n el 2001, se nos habló de San Pedro de Carabayllo, la antesala de Santo Toribio para sus visitas pastorales por el norte del Perú, cuando emprendía la visita pastoral para su gigantesca diócesis limeńa que acababa en Moyobamba. De modo particular, bendijo esta tierra cuando en Quives tuvo el honor de confirmar a la niña más célebre y universal de la historia del Perú, Santa Rosa de Lima.

1 Lección magistral. Inauguración del Año Académico, Universidad Católica Sedes Sapientiae, abril 2006. 
El segundo arzobispo de Lima vivió como nadie la cultura de la gratuidad colocando las bases de una cultura solidaria. Su primer biógrafo, León Pinelo, encarece el desprendimiento del prelado; «Testigo hay que le da la palma en ella [la caridad] y dice que se pudiera llamar Santo Toribio el Limosnero". Uno de los declarantes en el proceso de beatificación llegó a señalar que "para tener más que repartir, moderaba su gasto toda lo posible». El propio santo lo confesaba también en carta al Papa: «[...] distribuyendo mi renta a pobres con ánimo de hacer lo mismo si mucha más tuviera". Los agentes administradores de la caridad fueron sucesivamente el canónigo doctoral Juan de la Roca, obispo de Popayán; su sobrino, del mismo nombre, que fue arcediano de la catedral de Lima, y su primo y cuñado, Francisco de Quiñones y Villapadierna. Su mayordomo, muerto el santo, presentó una carta donde el arzobispo le instruía en que si para cumplir y pagar todas las limosnas que le había encargado no bastasen sus rentas, vendiese su pontifical para solventarlas. En la carta que escribe al papa Clemente VIII en 1598, señala lo siguiente:

De mi hacienda se ha distribuido de limosnas después que entré en este arzobispado, hasta ahora ciento cuarenta $y$ tres mil trescientos cuarenta y cuatro pesos y cuatro reales desde el año 84 hasta el 97, fuera de otras que se han repartido, á Dios sean dadas las gracias, por quien sólo esto se hace, en edificación de los prójimos, procurando darles buen ejemplo y animándolos á lo mismo. ${ }^{2}$

En el 2003, el entonces Decano de la Facultad de Ciencias de la Educación, Gian Corrado Peluso, disertó sobre la «Importancia de una educación por la pazm. En este discurso se mencionó que Santo Toribio, licenciado en derecho (civil y canónico) por la Universidad de

2 La transcripción se mantiene fiel al original, n. d. A 
Valladolid, de Salamanca y de Compostela, inquisidor en Granada, fue el gran educador constructor del Perú multicultural, un hombre de paz, pacífico y pacificador, que predicó y vivió que ael corazón de la paz es la paz de corazón".

El 16 de abril de 1596, el santo ofreció al virrey García Hurtado de Mendoza, Marqués de Cañete, su perdón, a pesar de haberle calumniado tildándole de "incapaz" y de andar con sus criados "comiéndoles la misma miseria que tienen" los indios. Buena prueba de ello es su carta: "Su Divina Majestad tenga misericordia de él y le perdone [...]. Yo me he alegrado y regocijado mucho en el Señor con estos trabajos y adversidades, y calumnias y pesadumbres, y los recibo como de su mano, y los tomo por regalo, deseando seguir a los Apóstoles y Santos Mártires, y al buen Capitán Cristo nuestro Redentor, con su ayuda y gracian.

El deseo de Santo Toribio de promover la dignidad del ser humano, muy en especial la del indio, se concretó en la fecunda y realista legislación de tres concilios provinciales (1583-1584, 1591, 1601) y de trece sínodos realizados en la Arquidiócesis de Lima, cuya importancia da fe su vigencia mantenida hasta el concilio plenario de América Latina, celebrado en Roma el año 1899. Podemos fijarnos en su decidida apuesta por los derechos humanos, la promoción social de los naturales, Así, el sinodo de 1585 especificó distintas situaciones relacionadas con los derechos sociolaborales del indio:

Que los indios de los obrajes vengan a la dóctrina a las iglesias los días de obligación entre semana [...], Y donde los dichos obrajes estuvieren distantes en manera que no puedan acudir a la Doctrina los dichos días de obligación sé les provea de sacerdote [...] para que los indios de los dichos obrajes puedan ir a trabajar a ellos, mandamos a los curas de indios digan la Doctrina muy de mañana para que los indios puedan ir a sus labores. (c. 54) 
JOSÉ ANTONIO BENITO

De igual modo, luchó por su trato privilegiado y favorable. En virtud de su condición de "plantas nuevas en la fe" se les otorgarían privilegios especiales:

[...] no hay cosa que en estas provincias de las Indias deban los prelados y los demás ministros [...] rener por más encargada y encomendada [...] que el tener y mostrar un paternal afecto y cuidado al bien y remedio de estas nuevas y tiernas plantas de la Iglesia [...]. Y ciertamente la mansedumbre de esta gente, y el perpetuo trabajo con que sirven $y$ su obediencia y sujeción natural podrían con razón mover a cualquier hombre por áspero y fiero que sea, para amparar y defender estos indios. (C3L, III, 3)

En el 2005, el padre César Buendía presentó la conferencia inaugural «Necesidad de los sacramentos, necesidad de Cristo". Al respecto, cabe serialar que nuestro santo prelado escribió a Felipe II, desde Andages, el 13 de marzo de 1589, que «los sacerdotes diocesanos son muy observadores en administrar los santos sacramentos, así el de la Eucaristía por Pascua de Resurrección, de la comunión mensual y frecuente, y de llevar el viático a los indios, según y como les está ordenado por constituciones de este Arzobispado". Fue constante su preocupación en fomentar el culto, amor y devoción al santísimo sacramento de la eucaristía y a la santísima Virgen.

El padre Buendía ańadía lo siguiente (con nadie encaja de modo tan preciso como con Santo Toribio):

[...] la vida del hombre es plena cuando en vez de mirarse en el espejo idolátrico del servicio a sí, olvidándose de sí mismo, se dedica a amar, a dejar de pensar en sí mismo, a alegrarse del bien ajeno, a buscar intensamente el bien de todos, como recuerda la parábola del buen samaritano 
referida a Cristo. Extrañamente, vino por nosotros. Exrrañamente, no retuvo como una presa el ser igual a Dios, en su ser es amor como hemos visto en nuestro último Papa, que no se retuvo. Se donó. Se cansó. Luchó. Vivió para Dios y para los demás. Era un sacerdote. Un verdadero apóstol.

Resulta imprescindible enfatizar en cinco aspectos de su vida para acercarla a la nuestra, aquí y ahora: la trascendencia histórica del universitario Toribio Alfonso de Mogrovejo, padre de América; Rosa de Lima y el comienzo de la santidad en Perú; las visitas pastorales de Santo Toribio al Perú profundo; la confirmación de Santa Rosa; Quives, capital de la santidad.

\section{La trascendencia histórica del Santo Padre de América}

Nuestro protagonista se ubica en la España de los Austria, más en concreto, en la de Felipe II. Probablemente, nace un 16 de noviembre de 1538 en la villa de Mayorga (Valladolid), encrucijada de caminos, entre las actuales comunidades autónomas de Castilla-León, Asturias, Cantabria y Galicia. En 1551, inicia sus estudios de gramática y humanidades en Valladolid, capital del mundo hispánico. En 1562, acude a Salamanca, donde enseña su tío Juan Mogrovejo, catedrático universitario. En 1569, obtiene el título de bachiller en Cánones, y en 1571 peregrina a Compostela y se licencia en derecho. Cuando cursaba estudios de doctorado en el colegio San Salvador de Oviedo, en 1574, se le nombra para Granada como inquisidor apostólico. El 16 de marzo de 1579 - en el consistorio de cardenales - el papa Gregorio XIII lo nombra arzobispo; contaba con 39 años y tan solo había recibido la tonsura clerical que era requisito en los colegios mayores y necesitó una apurada ordenación sacerdotal como paso indispensable para la 
JOSÉ ANTONIO BENITO

consagración episcopal. En 1581, llega a Paita y hace su entrada en Lima el 12 de mayo. En 1583, tiene lugar el tercer Concilio Limense, del que emanan tres grandes publicaciones en quechua, aymara y español: el catecismo, el sermonario y el confesionario. Conviene recalcar que son las primeras obras impresa en América del Sur (antes no había libros, pues las lenguas americanas eran ágrafas, sin escritura) y que marcan el comienzo de la literatura en América del Sur (pocos años antes se había publicado en Valladolid, la primera gramática en quechua). En 1584, comienza su primera visita pastoral. En 1591 , acomete una obra decisiva, la creación del seminario que - dedicado en su día a Santo Toribio de Astorga - hoy lleva su nombre. Sc siente, ante todo, pastor dispuesto a dar su vida por sus ovejas. A tal efecto crea nuevas parroquias. De igual modo, impulsará instituciones destinadas a la formación de líderes espirituales, académicos y sociales, en los monasterios como el de Santa Clara, hospitales como el de San Pedro, la Universidad de San Marcos, la Casa del Divorcio, etc. Visita todo su dilatado territorio y fallece en la cuarta visita general el 23 de marzo de 1606, en Saña. Al año siguiente, 1607, el 27 de abril, es enterrado en Lima. En 1679, fue beatificado, y en 1726, canonizado junto a san Francisco Solano y san Juan de la Cruz, entre otros.

Con la ley en la mano, su rostro "lleno de alegría", acariciando a todos con su mirada y con el amor de Dios en el corazón, roturará la geografía del Perú, humanizándola, asentando la nueva cristiandad de las Indias confirmando a sus hermanos. Gracias a un carácter equilibrado, armónico, evangeliza sin imposiciones, hermana razas sin abrir heridas, crea lazos forjados en amistad exigente y gratuita. Sobre rodo, se entrega de lleno a la tarea de formar, desde el seminario, una minoría selecta con su clero que esculpirá un nuevo rostro en el nuevo ser del Perú: un Perú forjado en la santidad, un Perú aglutinador de culturas, multicultural. Además de rraducirse al quechua y aymara, 
en el concilio se urgió a los obispos sufragáneos a que tradujeran el catecismo a las lenguas propias de sus obispados. Hubo, en efecto, muchas traducciones: en Quito se tradujo a la lengua tollana, cañeri, purgay, quillasinga; en el sur del Perú, entre Arequipa, Moquegua y Cusco, al puquina; en Chile, al araucano; en Paraguay, al guaraní, y en Santa Fe de Bogotá, al muisca. En cuanto a la impresión, viendo que era muy difícil imprimir la obra en España, "por no se poder llevar a imprimir a nuestro reinos de Castilla por no poder ir allá los correctores de las dichas lenguas quechua y aymarán (Doctrina Christiana y Catecismo 192), y porque en el Perú no había autorización para imprimir libros, encomendaron el trabajo a Antonio Ricardo, impresor que había llegado con su imprenta a Lima procedente de México en 1581. Empezaron a trabajar antes de haber obtenido la licencia, por considerar que no se podía perder tiempo y que el rey, vista las circunstancias y el interés que tenía en la evangelización de los indios a pesar de la resistencia, lo iba a conceder. Antonio Ricardo se instaló en el colegio de San Pablo de los jesuitas, el mismo local que hoy corresponde a la Biblioteca Nacional. La impresión de la obra tuvo un gran mérito por ser el primer libro impreso en Perú, por su extensión de casî 800 páginas y por presentar simultáneamente los textos en las tres lenguas: castellano, quechua y aymara, es una verdadera joya bibliográfica. La constitución política de 1993, en el artículo 2 , inciso 19 , reconoce y protege la pluralidad étnica y cultural de la nación y, en el artículo 48, declara que son idiomas oficiales el castellano $y$, en las zonas donde predominen, el quechua, el aymara y las demás lenguas aborígenes, según la ley. La norma constitucional "según la ley" no precisa cuál es la ley aplicable. Fue Santo Toribio el protagonista de esta obra normalizadora linguíística en el concilio. 
JOSÉ ANTONIO BENITO

\section{Rosa de Lima y el comienzo de la santidad en el Perú}

Recordemos que en 1548 Gaspar Flores, el padre de Santa Rosa, se avecina en Lima, doce años después de que el trujillano Francisco Pizarro, un 18 de enero, funde la Ciudad de los Reyes, Lima. El virrey Andrés Hurtado de Mendoza le nombra arcabucero para la guardia de su palacio. Nueve años después, en 1557, justo cuando España triunfa sobre los franceses en la batalla de San Quintín y el rey Felipe II ordena construir El Escorial, Gaspar celebra bodas con una limeña, María de Oliva, quien en el proceso de canonización de su hija Rosa nos dice que tuvieron trece hijos. Nuestra santa fue bautizada con el nombre de Isabel Herrera, como su abuela (así consta en el registro de bautizos de la parroquia de San Sebastián realizado por don Antonio Polanco: «En Dorningo día de Pascua del Espíritu Santo, 25 de Mayo de 1586, bauticé a Isabel, hija de Gaspar Flores y María de Oliva, fueron padrinos Hernández de Valdez y María Orozcon). Rosa es la cuarta de los supervivientes. Por esa fecha, 1586, se remata la cúpula de San Pedro de Roma.

Atraída por el ejemplo de Santa Catalina de Siena, aprendió a leer y escribir y a realizar todas las labores domésticas (costura, bordado, tejido), que eran una fuente de recursos, así como a cantar; también llegó a tocar el arpa, la vihuela, la cítara y tañer la guitarra. Su madre deseaba para su hija un casamiento ventajoso, pero Rosa optó por ser laica consagrada al estilo de santa Catalina de Siena. El 10 de agosto de 1606 viste el hábito de terciaria dominica, emite votos privados de pobreza, castidad y obediencia y vive su consagración en el hogar paterno. En el huerto de su casa construye una pequeña celda donde pasa los días dedicada a la oración, a la lectura y al bordado. Sale de su casa solo para asistir a misa y visitar hospitales, a pobres, a esclavos enfermos. En los últimos años sufre una larga enfermedad, durante la cual dice a menudo: «Señor, auméntame los sufrimientos, 
pero auméntame en la misma medida tu amor». Antes de morir le pide perdón por todos los pecados a cada uno de los de su casa. Muere exclamando "Jesús, Jesús sea conmigo" el 24 de agosto de 1617, a los 31 años de edad. Canonizada en 1671 por Clemente X y proclamada pacrona de América y de Filipinas; su cuerpo descansa en el convento de Santo Domingo de Lima.

El catecismo de la iglesia católica recogé dos momentos de la vida de nuestra santa, tomados de la primera biografía, la del P. Hansen, publicada en Lovaina en 1668. El primero alude a su vida de gozosa cruz: "Fuera de la Cruz no hay otra escala por donde subir al cielon (CIC n. ${ }^{\circ}$ 618); el segundo, referido a su amor por los pobres: «El día en que su madre le reprendió por atender en la casa a pobres y enfermos, Santa Rosa de Lima le contestó: "Cuando servimos a los pobres y a los enfermos, servimos a Jesús. No debemos cansarnos de ayudar a nuestro prójimo, porque en ellos servimos a Jesús» (CIC n. ${ }^{\circ} 2449$ ).

\section{Las visitas de Santo Toribio}

Así resume su vida su primer biógrafo, A. León Pinelo: "Fue su vida una rueda, un movimiento perpetuo, que nunca paraba». Le servirán al prelado para mantener un contacto directo con los sacerdotes y sus fieles; a nosotros nos aporta valiosísimos datos para una radiografía del Perú: censos de población, tipos de cultivos y ganados, condición y calidad de los doctrineros, comportamiento de los corregidores, trato recibido por los indios, situación y distancia de los caminos, condiciones meteorológicas, menú de los acompañantes del obispo, estudio etnográfico, estado del proceso evangelizador, etc.

Conocemos esta actividad por varias fuentes, las cartas (unas 75), los testimonios del proceso de beatificación (12 legajos) y el Libro de las Visitas (escrito entre 1593 y 1606), aún inédito. Las 
JOSÉ ANTONIO BENITO

grandes visitas pastorales, generales o formales, fueron emprendidas a continuación de los concilios provinciales limenses de 1583-4, 1591 y 1601. Hay que añadir, además, la de 1605-1606. Sus visitas eran auténticos encuentros vitales con los indios y sus curas doctrineros. El orden invariable seguido es un fiel reflejo de lo ordenado en los cánones del tercer Concilio Limense. Apenas llegado a un pueblo, se dirigía a la Iglesia donde permanecía largo tiempo, a veces horas enteras, en oración. Si era antes de mediodía, celebraba la Santa Misa. Sin perder un minuta visitaba las iglesias, monasterios, cofradias, hospitales, obrajes de indios... todos los lugares donde pudiese encontrar a sus fieles. Durante la visita, no recibía jamás el pequeño obsequio de nadie y para no ser gravoso a los párrocos rurales no permanecía en una población más del tiempo necesario. Confirmaba y predicaba, en quechua, con celo admirable, sin parar mientes en su cansancio. En su carta dirigida al rey Felipe II, desde Trujillo, el 10 de marzo de 1594, se puede leer:

[...] sin atender a más que al servicio de Nuestro Seńor [...] visitando mis ovejas y confirmando y ejerciendo el oficio Pontifical por caminos muy trabajosos y fragosos, con fríos y calores, y ríos y aguas, no perdonando ningún trabajo, habiendo andado más de tres mil leguas y confirmado quinientas mil ánimas, y distribuyendo mi renta a pobres con ánimo de hacer lo mismo si mucha más tuviera, aborreciendo el acesorar hacienda.

En la carta que escribe al papa Clemente VIII en 1598 nos da la verdadera razón de estas visitas: uen las visitas, no se ha aplicado ninguna cosa para mí ni llevado nada, y á los indios que se han confirmado no he consentido que me ofrezcan candelas ni plata, ni rraigan vendas, sino de mi hacienda se han puesto las candelas y vendas, 
que todo ello me valiera mucha cantidad, en razón de tanto número de indios, como se ha hecho bien de ver y de dar á entender, deseando todos los naturales tengan mucho contentamiento y no entiendan se les lleva algo por la administración de los santos sacramentosm.

Primera visita (1584-1591)

La primera visita tuvo lugar de 1584 a 1591 . Acabado el tormentoso pero fecundo tercer Concilio Limense, en diciembre de 1583, convoca el sínodo de 1584 para dar cuenta a los clérigos de Lima de lo ordenado en el Concilio. Hasta abril se ocupa en ordenar sacerdotes y confirmar en la iglesia limeña. Tras los intensos días de Pascua, a fines de abril de 1584, emprende una visita de siete años de duración, hasta 1591. En julio de 1584, se encuentra en la costa norte, Arnedo o Chancay, y el 19 de diciembre en Cajacay, más allá de Pativilca, y en dirección al Callejón de Huaylas o Ancash. En enero de 1585 visita toda la zona, deteniéndose para celebrar en Yungay, en plenos Andes, el tercer Sínodo Diocesano. A fines de enero regresa a Lima y en abril ya lo tenemos en Huaraz, en mayo en Recuay y en junio nuevamente en Huaraz. Fue al norte por Pallasca y los Conchucos, entrando en Cajamarca, de donde continuó hasta Chachapoyas, cruzando el río Marañón posiblemente por el puente de Balsas. Se dirige hacia Huacrachuco en mayo de 1587 y en diciembre entra en la zona de Huánuco. En enero de 1588, se encuentra en Conchamarca y en abril regresa a Lima para consagrar al obispo de Panamá. Vuelve a Junín y en junio lo vemos en Sicaya, pasa a Huarochirí y en diciembre llega a San Damián. Durante los meses de febrero y abril de 1589 recorre Cajatambo y Checra, para arribar de nuevo a la ciudad de los reyes en enero de 1591, donde inaugura las sesiones del cuarto concilio limense. 
JOSÉ ANTONIO BENITO

Segunda visita (1593-1598)

La segunda visita de Santo Toribio de Mogrovejo se realizará desde 1593 a 1598. Ancash (cerca de Chapín), Trujillo, Lambayeque, Cajamarca, Chachapoyas, Moyobamba. Contamos con el diario de la segunda visita aún inédito. En estos años, atiende 350000 fieles. Conservamos un valioso documento, el "Diario" de la visita، La inicia el 7 de julio de 1593, en la doctrina de Carabayllo, hoy englobada en la gran Lima hacia el kilómetro 32. La primera página descriptiva es la seis y nos informa que el Arzobispo comienza la visita el 7 de julio de 1593 en Carabayllo a 4 leguas de Lima y que tiene como cura al fr. Diego de Haro, de la orden de Nuestra Señora de la Merced, buen lenguaraz. Los indios resultantes son: Tributarios, 60. Reservados, 8 , De confesión, 200. Ánimas: 249 (chicos y grandes). Sínodo, 190 pesos ensayados. Cofradia del Rosario con jubileos y sin renta. Firmado: Fernando de Almansa, público notario. Confirmó: 43. De aquí se dirige hacia Aucallama, en el valle de Chancay, Palpa y Huaral, para continuar por Huacho y Huaura. El 24 de julio estaba ya en Totopón, junta al río de la Fortaleza o Pativilca, de donde continuó a Cajacay. De aquí pasó al Callejón de Huaylas, se desvió a Casma y, por la costa, se dirigió al norte hasta Jayanca. Vuelve hacia Pacasmayo, sube a Cajamarca, de donde por Pallasca, penetra en Huaylas llegando a Llamellín en febrero de 1595. Varía de rumbo, pasa a Chachapoyas para volver a Huamachuco $y$ ascender de nuevo a Cajamarca $y$ Chachapoyas. En 1598, nuestro Santo obispo Misionero, continuó con su visita saliendo nuevamente de su sede episcopal para visitar los suburbios, y por el norte llegar hasta Chancay y por el sur hasta Ica. 


\section{Tercera visita (1601-1604)}

La comenzó el 8 de agosto de 1601. Recorrió las provincias de Canta, Huarochirí, Yauyos, Cañete y nuevamente Ica. En setiembre está en Sisicaya, Chorrillos. En este viaje llegará a la frontera de infieles al valle de Huancabamba y donde atravesará peripecias sin cuento. El diario nos da cuenta de su paso por Carabayllo, Canta, Huamantanga, San José, Cauzo, Bombón, Paucartambo, San Miguel de Ullucmayo, Vico y Pasco, San Rafael y Las Yaras. En 1602, retrocede por la misma ruta y permanece hasta pasada la semana santa en Lima, Posteriormente, en abril de 1602, toma la ruca hacia Junín y Huánuco, por Sisicaya, Chorrillos, Yauyos, Carabayllo (Quivi, Canta, Guama), Naupa en Tarma, Pueblo de Guanisque, Santiago de Vitis, San Pedro de Pinos, Atunyauyos, Santo Tomingo de Cochalarano, San Francisco de Huanta, Tupi, San Francisco de Anco, Cajamarca de la Nasca, Palpa, Lurin, Chancha, Cañete, Coayllo, Santa Inés, Santiago de Crampoma, Asiento de la Asunción, San Marcelo de Huánuco, San Juan de Matorna, San Damían, San Lorenzo de Quinti, Repartimiento de Jauja, Hananqguaca, Luringuana, Pueblos de Andes (Cochangua, Santo Domingo de Paucarbamba, Andamarca, Santiago de Comas, Uchubamba), Tarma, Santa Ana de Pampas, San Jerónimo de la Oroya, Vilco y Palco, San Juan de Odores, San Juan de Huaylas, Pueblo de San Agustín, Cauzo, San Juan de Paucarbamba.. Regresa por Cajatambo y Chancay en 1604.

Después de visitar minuciosamente la Catedral, inventariando sus bienes, parece que el arzobispo marchó a su cuarta visita con el presentimiento de no volver a la ciudad de los reyes. Así lo refiere su secretario Diego de Morales, quien recoge las palabras de despedida del santo a su hermana Grimanesa: «Hermana, quédese con Dios, que ya no nos veremos más". 


\section{Cuarta visita (1605-1606)}

Después de descansar por un breve tiempo en Lima, reinició su Visita Pastoral el 12 de enero de 1605, partiendo de Carabayllo, hacia Ancón, Huacho, Palpa, y Aucallama. Tras recorrer las provincias de Chancay y Barranca y, seguir el curso del río Pativilca, giró hacia la derecha y visitó algunos distritos de Cajatambo; de aquí pasa al Callejón de Huaylas y, bajando a la costa por Casma, se dirige al norte hacia los valles de Pacasmayo y Chiclayo. Seńala su secretario de visita, Almansa, que el arzobispo «ha pasado grandísimos trabajos y cansancio en la prosecución de su visita, por ser este arzobispado de caminos fragosos y despeñaderos de mucho peligro, y ríos muy caudalosos y temples y cordilleras muy desabridas, y por las cuales su Señoría Ilustrísima ha pasado sin regalo alguno, que, como Príncipe, podía llevar; sólo por no dar molestia a los indios, no permitiendo que vayan cargados con cargas suyas ni de sus criados, ni que en nada se les dé trabajo». Cíta cómo él mismo estuvo a punto de perder la vida junto con su arzobispo al cruzar uno de los ríos cercanos a Trujillo y también saliendo a la sierra "sino se hallara un criado junto a él en un paso borrascoso, donde cayó de la mula, se despeñaram. Todo ello "por sólo querer ver y visitar por vista de ojos a los indios, aunque éstos metidos en montañas y tierras ásperas, a donde muchas veces es menester ir a pie por no haber caminos para caballos». Recoge un testigo que animaba a sus servidores diciéndoles que irían "como unos reyes, con nuestros bordones y alpargatas".

En plena visita pastoral por el norte del Perú, al llegar al santuario de Nuestra Señora Guadalupe, comenzó a sentirse mal. Nos cuenta el Padre Julián de la Torre y Escobar, Dean y Comisario de Cruzada de Trujillo, en el proceso de beatificación de 1631, que ael día antes que cayese malo de la enfermedad de que murió, saliendo del convento de Guadalupe con todos los frailes y el Prior 
para caminar después de medio día estando presente este testigo preguntó si era hora de caminar y le respondieron que sí, que ya corría la marean. Dijo: «No digo de eso sino para la otra vida». "Pas tecum "con que se despidió de los frailes y otro día por la mañana amanecería malo de un corrimiento a un pie de que dentro de doce días murió y así tiene por cierto este testigo" que sabía la hora de su muerten (ff.758-761).

Sigue hasta Chérrepe y Reque, de donde se encaminó a Saña. Juan Nińo de Velasco, de 62 años de edad, sacerdote, cura beneficiado de la iglesia parroquial de Zaña, declara que lo conoció justamente cuando le llevaron enfermo del pueblo de Reque. Le acompaña su fiel escudero Sancho de Ávila que pronto se ve ayudado de una abigarrada muchedumbre de españoles, mestizos, indios y negros Anochece en la antigua villa de Santiago de Miraflores, Toribio presiente la agonía en la humilde casa del párroco Juan de Herrera. El médico le advierte de su enfermedad mortal y procura aplacar sus dolores; Mogrovejo saca fuerzas de flaqueza y con sus ojos llenos de luz, exclama: "iQué alegría cuando me dijeron: Vamos a la casa del Señor!n.

Da como recompensa al buen médico lo único que le quedaba, su mula, y recuerda a sus acompañantes el compromiso de honor con su cuñado y limosnero Francisco de Quiñones de repartir entre los pobres lo que se obtenga de la venta de sus vestiduras litúrgicas. La noche no quiere acabarse, cuando tarda en romper la aurora. El enfermo sabe que es Jueves Santo, 23 de marzo de 1606 y pide ser llevado a la iglesia para recibir la Unción de Enfermos. Su capellán, Juan de Robles, con lágrimas en los ojos, no acierta a concluir. Toribio, más tranquilo, pide al prior agustino que tańa el arpa. fray Jerónimo Ramírez no se hace de rogar y acompaña el suave canto del agonizante: "A $\mathrm{A}$ Ti, Señor, me acojo:... En tus manos encomiendo mi espíritu!". 
JOSÉ ANTONIO BENITO

\section{El sacramento de la confirmación}

Acerca de este sacramento, debe tenerse en cuenta que tan solo los fieles de parroquias urbanas o cercanas a ellas, tenían la posibilidad de recibirlos ordinariamente. El resto de los cristianos debian esperar al paso de la visita pastoral, ya que los sacerdotes no estaban facultados para administrarla. Según esto, en muchísimas parroquias alejadas de la sede episcopal el único confirmando era el párroco. Por ello, no debe extrañarnos que fungiese de padrino de la mayoría de los fieles. Sucedió en ocasiones que muchos sacerdotes recibieron el mismo día de las órdenes menores y el subdiaconado, la confirmación. Por su parte, el tercer Concilio Limense (Lima, 1583) explica que el sacramento de la confirmación se da «a todos los cristianos bautizados, para que tengan fortaleza en la fe y ley de Dios contra sus enemigos". De modo explícito se prescribe que «cuando se da el sacramento de la confirmación a los indios no se les pida plata ni dinero alguno ni aún les persuadan a que lo traigan, antes a los indios pobres el obispo les provea de candelas y vendas liberalmenten.

Fiel a lo prescrito en los concilios limenses (C2L, I, 48) de que "todos los que se confirman se asienten en el libro", en el citado Libro de Visitas se da razón de los confirmados en Lima de 1592 a 1597 y de 1601 a 12 de enero de 1605, sumando 2262. Cuando escribe en 1590 al papa Sixto V le habla de 450000 confirmaciones. Al dirigirse al papa Clemente habla de más de 600 000. Su sobrino sacerdote Luis de Quiñones, en 1607, habla de 800 000, la cifra que parece más real. El prelado se entrega de lleno al ministerio. Sancho Dávila, que tan cerca estuvo siempre del Santo, nos explica en 1632 cómo confirmaba: 
Confirmó en su Arzobispado más de 1000000 almas y de las más de ellas fue este tesrigo padrino de ellos, [... ] y nunca consintió que le ofreciesen plata ni otra ofrenda y no llevó velas ni yendas a ningún indio y se enviaron a esta ciudad de los Reyes por un quintal de velas y cien varas de roan. Gastadas $y$ acabadas aquellas, enviaron por otras tantas y si algún indio llevaba alguna candela, se hacia volver a su casa y las velas que daban los puebles las dejaba a las Iglesias de los pueblos que si hubiese de llevar ofrendas candelas y vendas de los que confirmó, le debieran grandísima suma de hacienda. Cada indio llevaba su candela y venda de confirmando como regalo del Arzobispo. Si el material no llegaba de Lima, ordenaba romper las sábanas de su cama. Y muchos días entraba a confirmar en las doctrinas sin desayunarse con cosa alguna y a puertas cerradas quedaban dentro de la.Iglesia dos y tres mil ánimas, las cuales confirmaba todos, sin salir a comer si no era hasta la tarde, cuando se acababa, que solia ser a las cinco de la tarde [...] que causaba gran admiración y espanto.

El mismo Sancho Dávila, atento y fiel observador, recoge un caso particular y entrańable; «Y vio que estando un negro enfermo en su casa a deshoras de la noche habiéndolo catequizado y hecho capaz para recibir el viático, se lo trajeron y fue el dicho sr. Arzobispo por el con el Cura y volvió y lo consoló y después lo confirmó en su mismo aposento, donde entró Su Señoria para el dicho efecto y de allí adelante quedó sano y bueno que admiró esta acción a todos los que se hallaron presentes".

Este mismo fidelísimo ayudante, Sancho Dávila, cuando fue llamado a declarar en vida del Santo, en 1595, dará pormenores de la confirmación en circunstancias especiales como la concurrencia masiva de fieles o en caso de epidemia: 
JOSÉ ANTONIO BENITO

Por abreviar y darse prisa no confirmaba sentado, como otros Prelados hacían, sino haciendo en la Iglesia muchas hileras de los indios e iba por cada una confirmando en pie, sufriendo su hedor, que en algunas partes era insufrible, $y$ algunas veces confirmaba a las mil ánimas juntas [...]. En especial, en el tiempo de las viruelas y peste general que hubo en este reino, que por estar todos los indios en sus casas caidos con la dicha enfermedad, se andaba el dicho señor Arzobispo de casa en casa, a confirmarlos, sufriendo el hedor pestilencial y materia de la dicha enfermedad. ${ }^{3}$

\section{Quives, capital de la santidad}

Quives se encuentra camino a Canta, específicamente en el kilómetros 63 de dicha vía. El padre de Santa Rosa, Gaspar Flores, arcabucero en la guardia del palacio del Virrey, fue nombrado administrador de un obraje situado en las cercanías de Quives en el que permaneció por espacio de cuatro años. Acerca de la condición socioeconómica de la familia, parece que nunca fue alta. Don Gaspar nunca alcanzó a tener una encomienda y tampoco participó en el grupo social alto de la ciudad. Sus ingresos a duras penas alcanzaban para mantener a su numerosísima familia. Un año antes de nacer Rosa, fue contratado como administrador de minas en Cajatambo en 1585. En 1595 fue contratado para administrar el obraje de Quives, donde trasladó a toda su familia. En 1598 sería la confirmación. Rosa comprobó y vio esa realidad. Cuando ella tenía 14 ańos, estando en Quives, los mineros fueron requeridos para duplicar la producción minera y establecieron dos turnos, uno de día y otro de noche. Se agravó tanto en 1600 , que para que los mitayos mineros no perdieran tiempo en subir y bajar a los socavones, los retenian en el interior encerrándolos en el subsuclo

3 C. García Irigoyen II, 134. 
desde el lunes por la tarde hasta el sábado por la tarde. Aunque hubo intentos de mejorar la situación por parte de autoridades como el virrey Conde de Lemos en 1600 los explotadores amenazaron con para liar la producción minera y tuvo que dejar las cosas tal y como estaban. Consta que después de cuatro anios de explotación, la mina de Quives se derrumbó.

La doctrina de Quives estaba al cuidado de los religiosos de la Merced. Rosa se dispuso a recibir el sacramento de la confirmación y, siendo su padrino el cura doctrinero del pueblo, Francisco González, recibió la unción sagrada de manos del virtuoso prelado. Tal sentir coincide con las escasas fuentes que recogen datos sobre el menester: Actas del Proceso de Beatificación, diario de la visita de Santo Toribio, primeras biografias de ambos santos. Veamos lo que hemos documentado por el momento. En el Auto del Cuestionario para el Proceso de Beatificación, del 5 de setiembre de 1617 , en la pregunta tres se dice whasta que siendo de edad de once años poco más o menós, el señor don Toribio de Mogrovejo, Arzobispo de esta ciudad, hizo órdenes de confirmación en el pueblo de Quivi, nueve leguas de esta ciudad y confirmó a la dicha santa nińa en el nombre de Rosa de Santa María. Refuerza esta información el testimonio del Contador Gonzalo de la Maza, quien afirma que uesto (el llamarse Isabel) duró hasta que el seńor Arzobispo don Toribio Alfonso de Mogrovejo lo confirmó". El padrino sería el cura de la doctrina don Francisco González, el mismo que aparece en la relación de curas prebendados del 30 de abril de 1602 presentados por el virrey. En Quives se encuentran en la actualidad los misioneros de Nuestra Señora de la Reconciliación y del Sefior de los Milagros. En el jardin del Santuario se conserva una piedra de molino de la época utilizado para triturar los minerales en el obraje. En el altar interior se ha incrustado la piedra donde la santa se reclúa para orar. Una de las hermanas de Santa Rosa llamada 
JOSÉ ANTONIO BENITO

Bernardita que fue confirmada junto con ella murió en Quives y está enterrada a la entrada del templo.

Rosa vivió en Quives aproximadamente unos siete años a los 17 regresó a Lima y muere el 24 de agosto de 1617. En el Diario de la Visita del Santo Arzobispo, se menciona a Quives al resumir las leguas que el Arzobispo: «Ha andado en esta visita que hizo saliendo de esta ciudad de los Reyes en 8 de agosto de 1601 añosn. De Lima a Carabaillo 4 (leguas); de Carabaillo a Yungas 6 (leguas); de Yungas a Quivi I. La distancia es de 11 leguas. Al referir a los "confirmados que Su Señoría confirmó en la visita que hizo este año de 1602 son los siguientes: Villa Carabayllo, 9 personas; de Quivi (los siere pueblos como San Pedro de Yaco, Araguay, Visc, Santa Olalla, San Mateo), 557; de Canta, 556, y Guama, 648.

En 1598, tras vivir la Semana Santa en Lima, visita sus contornos y, tomando el camino del norte, se acerca el 12 de febrero de 1598 a Arnedo o Chancay y Canta. Esta visita se completó como se indicó anteriormente con otras visicas apostólicas como la de 1601 por Canta, Huarochirl, Yauyos, Cañete, Junin, Ica.

Como recuerdo de este singular momento, tenemos varias esculturas, cuadros, retablos y hasta templos. Cabe mencionar el retablo esculpido en madera policromada en la casa solariega de Mayorga con el grupo escultórico que representa a Santo Toribio confirmando a santa Rosa de Lima y que está bordeado por diferentes casetones con relieves alusivos a los momentos más destacados de su vida.

Fue Monseńor E. Lissón, C. M. arzobispo de Lima, quien colocó la piedra de la restauración de la ermita el 31 de agosto de 1924. El templo donde fue confirmada por Santo Toribio de Mogrovejo arzobispo de Lima y la misma casa fueron declarados monumentos históricos por Ley n. ${ }^{\circ} 10403$ del 23 de febrero de 1946. El conjunto recibió el nombre de santuario. Y no es para menos. Allí se produjo el encuentro del santo prelado Mogrovejo, patrono de todos los obispos 
de América Latina, con la primera y más grande santa de toda América, Rosa de Lima. Esto sucedió, no lo olvidemos en nuestra diócesís, en Carabayllo.

\section{Bibliografía}

Angulo, D. "Libro de Visitas, 1593", Revista del Archivo Nacional del Perú. (1920): I, pp. 49-81; 227-279; 401-419; (1921): II, pp. 37-78, 1921.

Libro de visitas de Santo Toribio (1593-1605). Introducción, transcripción y notas. Lima (en prensa), 2006.

León Pinelo, Antonio de. Vida del Ilustrísimo y Reverendísimo D. Toribio Alfonso Mogrovejo, Arzobispo de la ciudad de los Reyes. Lima, 1906 [Madrid, 1653].

Martí, M. Documentos relativos a su visita pastoral de la diócesis de Caracas 1771-1784. 7 vols. Caracas: Academia Nacional de la Historia, 1980.

Vargas Ugarte, Rubén. Santo Toribio, segundo arzobispo de Lima. Lima: Paulinas, 1989. 